Preface

\title{
Laboratory Assessment of Hemostatic and Anticoagulant Therapy
}

\author{
Dorothy M. Adcock, MD ${ }^{1}$ Robert C. Gosselin, CLS 2 \\ ${ }^{1}$ Colorado Coagulation, Laboratory Corporation of America ${ }^{\circledR}$ \\ Holdings Englewood, Colorado \\ ${ }^{2}$ Department of Pathology and Laboratory Medicine, University of \\ California, Davis Health System, Sacramento, California
}

Semin Thromb Hemost 2017;43:242-244.

This issue of Seminars in Thrombosis $\mathcal{E}$ Hemostasis is devoted to the laboratory assessment of therapies used in the prophylaxis and treatment of bleeding and thrombotic disorders. The laboratory assessment of hemostasis and anticoagulant therapies defines a critical role of clinical coagulation laboratories due to their direct and significant impact on patient care. Furthering the importance of such activity is the ever increasing and diversification in the administration of such therapies.

Thrombosis, through its association with ischemic stroke, ischemic heart disease, and venous thromboembolism (VTE), is a major contributor to our global disease burden. For example, the 2010 Global Burden of Disease Study reported that ischemic stroke and ischemic heart disease are responsible for one in four deaths worldwide. ${ }^{1}$ Also prevalent is VTE, with an annual incidence of 0.75 to 7.0 per 1,000 individuals, depending on geographic location and age, with an overall incidence of approximately 1 per 1,000 individuals. ${ }^{2}$ The worldwide incidence of atrial fibrillation, a population at risk for thrombosis who often received prophylactic anticoagulant therapy, is estimated at 33.5 million and the incidence of atrial fibrillation is increasing. ${ }^{3,4}$ Individuals at risk of, or suffering from arterial or venous thrombosis, are treated on a short- or long-term basis with fibrinolytic, antiplatelet, and/or anticoagulant agents. Annually, this encompasses hundreds of millions of individuals worldwide. The clinical laboratory is instrumental in the care of these patients and assists in determining safety of therapy before it is initiated, as well as monitoring the effects and complications of therapy to adjust dose, administer antidotes, or provide adjuvant therapies.

As an effective agent in providing long-term anticoagulation, oral vitamin $\mathrm{K}$ anticoagulation has been administered for over 50 years. To better standardize monitoring with the prothrombin time (PT), the international sensitivity index (ISI) and international normalized ratio (INR) were introduced by the World Health Organization in the 1980s. Despite this effort at standardization, clinically significant variability in PT/INR results persists, pointing to additional standardization measures needed..$^{5-8}$ Moffat et al therefore reviews the variables in the PT/INR and discusses the potential benefits of derived INR curves as well as the application of PT/INR testing to point-of-care devices. ${ }^{9}$

While unfractionated heparin has been used as an anticoagulant therapy for nearly 75 years, laboratory issues regarding optimum use of the activated partial thromboplastin time (aPTT) in monitoring therapy remain. ${ }^{10}$ Marlar et al thus provide an in-depth review of the determination and use of the aPTT heparin therapeutic range for use in monitoring. ${ }^{11}$ In part, as a response to issues associated with unfractionated heparin therapy and its monitoring, newer heparin agents have been introduced within the past 20 years, including low-molecular-weight heparin (LMWH) and fondaparinux. These agents generally do not require laboratory monitoring. The article by Babin et al provides special insight into those populations who may benefit from measurement of plasma drug concentrations to allow dose adjustment. ${ }^{12}$ Well-accepted laboratory means to assess drug concentration as well as newer available assays including thromboelastography and thrombin generation assays are extensively discussed. In those situations where heparin anticoagulation cannot be used, or is considered too risky, such as in patients with heparin-induced thrombocytopenia, a direct thrombin inhibitor may be administered. The article by Van Cott and colleagues provides valuable information about laboratory assays that can be used to monitor these therapies as well as to measure drug concentrations. ${ }^{13}$ This article also provides invaluable information regarding the transitioning from these agents to oral vitamin $\mathrm{K}$ anticoagulation.

After 50 years of having a relatively limited armamentarium of anticoagulant therapies available, a new class of oral,
Address for correspondence

Robert C. Gosselin, CLS,

Department of Pathology and

Laboratory Medicine, University

of California, Davis Health

System, Sacramento, CA 95817

(e-mail: rcgosselin@outlook.com).
Issue Theme Laboratory Assessment of Hemostatic and Anticoagulant Therapy; Guest Editors: Robert C. Gosselin, CLS, and Dorothy M. Adcock, MD.
Copyright $\odot 2017$ by Thieme Medical Publishers, Inc., 333 Seventh Avenue, New York, NY 10001, USA. Tel: +1(212) 584-4662.
DOI http://dx.doi.org/ 10.1055/s-0037-1601051. ISSN 0094-6176. 
fast acting, direct thrombin, and Xa agents has recently become available worldwide. While these agents were approved by U.S., European, and other regulatory agencies without recommended laboratory assays and recommended measured therapeutic drug concentrations, laboratories may be asked to provide tests that can be used to determine the presence or absence of drug. ${ }^{14}$ Douxfils and Gosselin discuss the patient populations that may benefit from laboratory assessment of drug presence and/or concentration and further advise which assays may best serve this purpose. ${ }^{15}$ Some information on sample collection and stability is also provided.

Extracorporeal life support is a life-saving strategy associated with the frequent occurrence of bleeding and clotting complications, often with ruinous outcomes. ${ }^{16}$ The demand for anticoagulation of the extracorporeal circuit and the acquired coagulation changes associated with this circuit are in part the basis for such complications. Dr. Winkler meticulously explains the complex and often multifactorial nature of these complications as well as anticoagulant management and measurement methods in patients on extracorporeal life support. ${ }^{12}$

Patients with acute thrombosis may be candidates for thrombolytic therapy. This therapy often induces complex systemic effects that greatly enhance the risk for bleeding. This often neglected area of therapeutics is highlighted by Kluft and colleagues in their intriguing review, which includes a means to assess safety prethrombolytic administration. ${ }^{17}$ Importantly, the effects of thrombolytic therapy on systemic coagulation are presented as well as suggested laboratory assays that can be used to assess posttherapy patient samples.

Another aspect of antithrombotic therapy comprises the administration of antiplatelet therapies, which is increasing in both the hospital and out-patient settings. Aspirin and clopidogrel remain the mainstays of therapy, although additional/alternative therapies are emerging. ${ }^{18}$ Orme and colleagues therefore discuss whether the oral agents need to be evaluated for resistance to therapy and whether patienttailored regimens have added clinical benefit. ${ }^{19}$ Different methodologies to monitor antiplatelet therapies are reviewed and the current status of platelet function testing highlighted.

Hereditary and acquired bleeding disorders, although not as common as thrombotic disorders, have a global basis and require hemostasis testing, both for diagnosis and for monitoring during the administration of appropriate therapies. Insufficient replacement therapy may lead to continued bleeding and over-administration to thrombotic risk. Accurate laboratory assessment is crucial to appropriate care and there are important nuances to providing the most accurate and clinically useful results. The recently introduced modified factors VIII and IX replacement therapies may show variable recovery in one-stage factor activity assays depending on the replacement factor and specific aPTT assay used. ${ }^{20}$ In the monitoring of post-von Willebrand factor (VWF) infusion samples, there is confusion as to whether factor VIII or VWF activity best correlates with bleeding risk. ${ }^{21}$
An accurate measure of factor VIII activity is crucial during FVIII replacement therapy, as well as in von Willebrand replacement therapy. Castellone and Adcock carefully review the critical components of factor VIII activity assays as well as inhibitor assays, to help laboratories optimize these assays. ${ }^{22}$ Kitchen and colleagues review the issues using one-stage factor activity assays in patients receiving modified recombinant factors VIII and IX replacement therapies as well as providing potential solutions to these issues. $^{23}$ Finally, Favaloro and colleagues describe the optimal array of assays for those undergoing therapy for von Willebrand disease (VWD) as well as how the interpretation of these assays may assist with the confirmation of type of VWD. ${ }^{24}$

The contemporary laboratory assessment of hemostatic and anticoagulant therapies comprises a critical role for the clinical laboratory in support of optimized patient care. We hope that readers of this journal find the current assortment of articles valuable to their practice. A good understanding of assays needed for monitoring therapy, together with their interpretation, will underpin laboratory practice, as this area of testing becomes ever more crucial in the evolution toward personalized medicine. We feel that this issue provides a unique compilation from many years of practical experience. We sincerely thank all of the authors to this special issue for their contributions and the tremendous wisdom that they provide.

\section{References}

1 Lozano R, Naghavi M, Foreman K, et al. Global and regional mortality from 235 causes of death for 20 age groups in 1990 and 2010: a systematic analysis for the Global Burden of Disease Study 2010. Lancet 2012;380(9859):2095-2128

2 ISTH Steering Committee for World Thrombosis Day. Thrombosis: a major contributor to the global disease burden. J Thromb Haemost 2014;12(10):1580-1590

3 Colilla S, Crow A, Petkun W, Singer DE, Simon T, Liu X. Estimates of current and future incidence and prevalence of atrial fibrillation in the U.S. adult population. Am J Cardiol 2013;112(8):1142-1147

4 Chugh SS, Havmoeller R, Narayanan K, et al. Worldwide epidemiology of atrial fibrillation: a Global Burden of Disease 2010 Study. Circulation 2014;129(8):837-847

5 Olson JD, Brandt JT, Chandler WL, et al. Laboratory reporting of the international normalized ratio: progress and problems. Arch Pathol Lab Med 2007;131(11):1641-1647

6 Kitchen DP, Jennings I, Kitchen S, Woods TA, Walker ID. Bridging the gap between point-of-care testing and laboratory testing in hemostasis. Semin Thromb Hemost 2015;41(3):272-278

7 Bonar R, Mohammed S, Favaloro EJ. International normalized ratio monitoring of vitamin $\mathrm{K}$ antagonist therapy: comparative performance of point-of-care and laboratory-derived testing. Semin Thromb Hemost 2015;41(3):279-286

8 Bonar R, Favaloro EJ. Explaining and reducing the variation in inter-laboratory reported values for International Normalised Ratio. Thromb Res 2016;150:22-29

9 Moffat KA, Lewis LC. Laboratory monitoring of oral vitamin K anticoagulation. Semin Thromb Hemost 2017;43(3):245-252

10 Smythe MA, Priziola J, Dobesh PP, Wirth D, Cuker A, Wittkowsky AK. Guidance for the practical management of the heparin anticoagulants in the treatment of venous thromboembolism. J Thromb Thrombolysis 2016;41(1):165-186 
11 Marlar RA, Clement B, Gausman J. Activated partial thromboplastin time monitoring of unfractionated heparin therapy: issues and recommendations. Semin Thromb Hemost 2017;43(3):253-260

12 Babin JL, Traylor KL, Witt DM. Laboratory monitoring of lowmolecular-weight heparin and fondaparinux. Semin Thromb Hemost 2017;43(3):261-269

13 van Cott EM, Roberts AJ, Dager WE. Laboratory monitoring of parenteral direct thrombin inhibitors. Semin Thromb Hemost 2017;43(3):270-276

14 Lippi G, Favaloro EJ. Recent guidelines and recommendations for laboratory assessment of the direct oral anticoagulants (DOACs): is there consensus? Clin Chem Lab Med 2015;53(2): 185-197

15 Douxfils J, Gosselin RC. Laboratory assessment of direct oral anticoagulants (DOACS). Semin Thromb Hemost 2017;43(3): 277-290

16 Winkler AM. Managing the precarious hemostatic balance during extracorporeal life support: implications for coagulation laboratories. Semin Thromb Hemost 2017;43(3):291-299

17 Kluft C, Sidelmann JJ, Gram JB. Assessing safety of thrombolytic therapy. Semin Thromb Hemost 2017;43(3):300-310
18 Elewa H, Ahmed D, Barnes GD. Triple oral antithrombotic therapy in atrial fibrillation and coronary artery stenting: searching for the best combination. Semin Thromb Hemost 2016;42(6): 662-670

19 Orme R, Judge HM, Storey RF. Monitoring antiplatelet therapy. Semin Thromb Hemost 2017;43(3):311-319

20 Dodt J, Hubbard AR, Wicks SJ, et al. Potency determination of factor VIII and factor IX for new product labelling and postinfusion testing: challenges for caregivers and regulators. Haemophilia 2015;21(4):543-549

21 Mannucci PM. How I treat patients with von Willebrand disease. Blood 2001;97(7):1915-1919

22 Castellone DD, Adcock DM. Factor VIII activity and inhibitor assays in the diagnosis and treatment of hemophilia A. Semin Thromb Hemost 2017;43(3):320-330

23 Kitchen S, Tiefenbacher S, Gosselin R. Factor activity assays for monitoring extended half-life factor VIII and IX replacement therapies. Semin Thromb Hemost 2017;43(3):331-337

24 Favaloro EJ, Pasalic L, Curnow J. Monitoring therapy during treatment of von Willebrand disease. Semin Thromb Hemost 2017;43(3):338-354 